\title{
REPENSANDO OS FUNDAMENTOS DA TEORIA CRÍTICA DE FRANKFURT E OS SEUS DILEMAS TEÓRICOS, EPISTEMOLÓGICOS E POLÍTICOS
}

Rethinking the foundations of the critical theory of the Frankfurt School and its theoretical, epistemological and political dilemmas

Paulo Vitorino Fontes *

Resumo: Neste artigo pretendemos revisitar e interrogar o sentido filosófico, sociológico e político desta realidade intitulada de Escola de Frankfurt, desde o seu início com Max Horkheimer e Theodor Adorno, até aos dias de hoje. Importa salientar a originalidade do projeto de Frankfurt, ao elaborar uma teoria crítica da sociedade que deu origem a um vasto programa de trabalho interdisciplinar, marcando profundamente o curso das ciências sociais não só na vertente marxista, que foi a sua raiz originária, mas também no panorama geral da teoria social contemporânea. Dada a pertinência deste empreendimento crítico, propomos repensar as ideias centrais e os pressupostos metodológicos que desde o início têm constituído o trabalho interpretativo da teoria crítica de Frankfurt; ao mesmo tempo que recorremos à crítica pós-moderna de Boaventura de Sousa Santos na discussão dos principais dilemas teóricos, epistemológicos e políticos que a teoria crítica hoje enfrenta.

Palavras-chave: Teoria crítica, Razão, Escola de Frankfurt.

Abstract: This article intends to revisit and question the philosophical, sociological and political meaning of the reality referred to as the School of Frankfurt, from its origins, with Mark Horkheimer and Theodoro Adorno, to today. It is

* Doutorado em Teoria Jurídico-Política e Relações Internacionais pela Universidade de Évora. Investigador colaborador do Centro de Investigação em Ciência Política (CICP) da Universidade de Évora. Artigo submetido a 20/01/2018 e aprovado para publicação a 11/07/2018. 
important to underline the originality of the Frankfurt project. By elaborating a critical theory of society, it gave birth to a vast interdisciplinary work program and deeply influenced the course of social sciences, not only in its Marxist strand, where it is rooted, but also from the general perspective of contemporary social theory. Given the pertinence of this critical undertaking, we propose to rethink the central ideas and methodological assumptions that, since the beginning, have been the basis for the interpretative work of the Frankfurt School critical theory. Simultaneously, we intend to explore Boaventura de Sousa Santos' post-modern critical thinking when discussing the most important theoretical, epistemological and political dilemmas faced by the critical theory today.

Key-words: Critical Theory, Reason, Frankfurt School.

\section{Introdução}

$\mathrm{R}$ epensar a Escola de Frankfurt parece essencial na tarefa a que nos propomos, embora não restem dúvidas da sua existência histórica, pelas inúmeras referências, estudos e autores e autoras que a reconhecem. Importa interrogar o sentido filosófico, sociológico e político desta realidade intitulada de Escola de Frankfurt. Não esquecendo que a Escola não se esgota nestas categorias, importa salientar a originalidade do projeto de Frankfurt, ao elaborar uma teoria crítica da sociedade que deu origem a um vasto programa de trabalho interdisciplinar, marcando profundamente o curso das ciências sociais não só na vertente marxista, que foi a sua raiz originária, mas também no panorama geral da teoria social contemporânea. Dada a pertinência deste empreendimento crítico, propomos repensar as ideias centrais e os pressupostos metodológicos que desde o início têm constituído o trabalho interpretativo da teoria crítica de Frankfurt; ao mesmo tempo que exploraremos os principais dilemas teóricos, epistemológicos e políticos qua a teoria crítica enfrenta nos nossos dias.

\section{Desenvolvimento da teoria critica alemã - Escola de Frankfurt}

A Escola de Frankfurt será a corrente que tomou forma em Frankfurt, através de um decreto do ministério da Educação, datado de 3 de fevereiro de 1923, como resultado de um acordo entre o ministério e a Gesellschaft fur Sozialforschung (Sociedade para a Investigação Social) que permitiu criar o Institut fur Sozialforschung (Instituto de Pesquisas Sociais). Sem o Instituto não teria havido Escola, mas esta extravasa do Instituto. Segundo Martin Jay, a "noção de escola específica só se desenvolveu depois que o Instituto foi obrigado a abandonar Frankfurt, só sendo mesmo o termo empregue 
após o regresso do Instituto à Alemanha em 1950". ${ }^{1}$ Sendo complexa a identidade deste projeto, verifica-se uma ambiguidade nos primeiros anos, em que os fenômenos sociais são pensados sob a influência de Hegel, Kant e Heidegger, numa mistura de filosofia e sociologia. Esta questão só se esclarece quando Max Horkheimer assume a liderança do Instituto em 1931, e a exigência metodológica passa a designar-se de filosofia social.

No período entre as duas guerras mundiais, os fundadores da Escola de Frankfurt elegeram o nome de teoria crítica para simbolizar a tentativa de conciliar teoria e prática, de alcançar a unidade da teoria com a investigação empírica e com a consciência histórica dos problemas sociais, políticos e culturais de uma determinada época. Segundo Craig Calhoun (1996, p. 437), estes desenvolveram a conceção programática do papel potencial que uma teoria crítica pode exercer no âmbito do discurso público auto reflexivo próprio de uma sociedade democrática.

Horkheimer na sua lição inaugural intitulada: "The Present Situation of Social Philosophy and the Tasks of an Institute for Social Research", na tomada de posse como diretor do Instituto de Frankfurt em 1931, enuncia a questão sobre a qual se funda a Escola de Frankfurt: "a questão da conexão entre a vida económica da sociedade, o desenvolvimento psicológico dos indivíduos e as mudanças na esfera da cultura". ${ }^{2}$ Para o pensador alemão, esta questão não é apenas de relevância atual, apresentando-se como uma versão contemporânea do conjunto de problemas filosóficos mais antigos e mais importantes. O projeto de investigação das relações entre os três processos enunciados será acima de tudo uma reformulação na base da nova constelação do problema, de acordo com os métodos de investigação disponíveis e com o nível de conhecimento acerca da antiga questão da ligação entre a existência particular e a Razão universal, da realidade e da Ideia, da vida e do Espírito, como define Horkheimer. ${ }^{3} \mathrm{O}$ autor enuncia de forma clara que uma Teoria Crítica da sociedade apta a assumir o complexo projeto de refletir acerca das suas origens sociais, assim como sobre as possibilidades políticas da sua realização prática, só pode cumprir esse objetivo num contexto interdisciplinar. O modelo apresentado para cumprir esse propósito é o de uma contínua interpenetração dialética entre a teoria filosófica e a prática científica concreta.

Segundo Jay, ${ }^{4}$ para além de Horkheimer deve-se incluir na primeira linha desta Escola o nome de Theodor Wiesengrund-Adorno, que proporciona

\footnotetext{
${ }^{1}$ JAY, Martin. La Imaginación Dialética: Una Historia de la Escola de Frankfurt. Tradução de Juan Carlos Curutchet. Madrid: Taurus, (1974) 1989, p. 14.

${ }^{2}$ HORKHEIMER, Max. The Present Situation of Social Philosophy and the Tasks of an Institute for Social Research. In Between Philosophy and Social Science: Selected Early Writings Studies in Contemporary German Social Thought. Tradução de G. Frederick Hunter, Matthew S. Kramer, e John Torpey. Cambridge: MIT Press, (1931) 1993, p. 11.

${ }^{3}$ Ibidem, p. 11-12.

${ }^{4}$ JAY, Martin, loc. cit.
} 
a alternativa teórica da Escola após o período de exílio. A que devemos juntar outras figuras ligadas à Escola, de formas diferentes, mas que contribuíram para a ampliação teórica dos seus princípios e métodos. Como foram Herbert Marcuse, Walter Benjamin e Erich Fromm, que constituíram o núcleo inicial. Interessa também citar os principais colaboradores do Instituto desde o seu início: Franz Borkenau, Henryk Grossmann, Otto Kirchheimer, Mira Komarovski, Siegfried Kracauer, Leo Lowenthal, Franz Neumann, Friedrich Pollock, Andries Sternheim, Félix Weil e Karl August Wittfogel. Importa também evocar o nome de Ernst Bloch, que partindo de princípios diferentes, através da conceção da utopia, foi ao encontro da teoria crítica.

Finalmente, é necessário acrescentar os herdeiros da teoria crítica, que não pertencendo ao grupo histórico dos fundadores, referem-se à teoria crítica nos seus trabalhos: é o caso de Alfred Schmidt, Oskar Negt, Karl-Otto Apel, Albrecht Wellmer, Claus Offe e, o mais destacado de todos, Jürgen Habermas. Mais recentemente, surge Axel Honneth, atual diretor do Instituto de Pesquisas Sociais de Frankfurt, sendo um dos mais importantes pensadores da terceira geração da Escola de Frankfurt.

O pensamento da Escola de Frankfurt combinava diversas influências, como o marxismo, a psicanálise, a filosofia e a teologia idealista alemã, o romantismo e os pensadores da «face oculta» das Luzes, como Nietzsche. A teoria crítica, enquanto projeto distinto, pretendia combinar a filosofia abstrata e universal tradicional com o conhecimento empírico e histórico do social, inspirava-se em Hegel e no diálogo mantido com ele, principalmente em Marx, como o mais importante daqueles que tentaram recuperar a capacidade crítica perdida, partindo de esquemas de raciocínio influenciados por Hegel. ${ }^{5}$

Para Axel Honneth, ${ }^{6}$ Hegel estava convencido de que as patologias sociais devem entender-se como o resultado da incapacidade das sociedades em expressar adequadamente nas instituições, nas práticas e nas rotinas quotidianas um potencial de razão que já está latente nelas. Esta concepção desemboca na tese geral de que uma forma conseguida de sociedade só é possível se for preservado o máximo da racionalidade desenvolvida em cada caso. Para Hegel, a justificação desta conexão é feita pela premissa ética de que só o universal racional pode indicar aos membros de cada sociedade os critérios de orientação através dos quais podem orientar as suas vidas com sentido. Segundo Honneth, ${ }^{7}$ esta convicção substancial

\footnotetext{
${ }^{5}$ CALHOUN, Craig. A Teoria Social e a Esfera Pública. In B. TURNER (ed.), Teoria Social. Tradução suportada pela Fundação Luso-Americana. Algés: Difel, 1996, p. 448-449.

${ }^{6}$ HONNETH, Axel. Patologías de la Razón. Tradução de Griselda Mársico. Madrid: Katz, 2009 , p. 31.

${ }^{7}$ Ibidem, p. 32.
} 
também está presente nos representantes da teoria crítica, quando nos seus diversos enfoques atribuem a causa das patologias da sociedade capitalista à falta de racionalidade social. A ideia hegeliana de que é sempre necessário um universal racional que possibilite a autorrealização plena dos sujeitos dentro da sociedade é retomada em diversas definições da práxis do ser humano: como o conceito de "trabalho humano" de Horkheimer, a ideia de "vida estética" em Marcuse ou o conceito de entendimento comunicativo em Habermas servem como princípio ao objetivo de estipular uma racionalidade em cuja forma desenvolvida é determinada a medida de uma integração racional e satisfatória da sociedade. A remissão a esta instância de praxis racional é que permite a estes autores desenvolver a sua análise da sociedade como um diagnóstico das patologias sociais baseado na teoria da razão: os desvios ao ideal que se alcançaria com a realização social do universal racional podiam ser descritos como patologias sociais, uma vez que estavam acompanhadas de uma perda dolorosa das oportunidades de autorrealização intersubjetiva. ${ }^{8}$

Os representantes da teoria crítica partilham com Hegel a convicção que a autorrealização do indivíduo só é conseguida se for conjugada nos seus fins com a autorrealização de todos os demais membros da sociedade, mediante princípios e propósitos aceites por todos. Como acentua Honneth, ${ }^{9}$ pode-se afirmar que na ideia de um universal racional está incluído o conceito de um bem comum, sobre o qual terão que colocar-se de acordo racionalmente os membros de uma sociedade, de forma a poder relacionar as suas liberdades individuais cooperativamente.

Segundo Honneth, ${ }^{10}$ a ideia de um universal racional da autorrealização cooperativa, que partilham todos os membros da teoria crítica, é tão crítica a respeito do liberalismo como da corrente de pensamento denominada de "comunitarismo". Todos os conceitos utilizados na teoria crítica articulam-se a ações cuja execução requer um grau de intersubjetividade maior do que aquele que se admite no liberalismo. Na teoria crítica pressupõe-se um ideal normativo de sociedade que é incompatível com os princípios individualistas da tradição liberal, mas que tem como orientação a ideia de uma autorrealização cooperativa, onde os sujeitos só poderão alcançar uma vida realizada na sociedade se reconhecerem para além dos seus interesses particulares um conjunto de convicções de valor compartilhadas.

Ao continuar este argumento, podíamos pensar que a teoria crítica e o "comunitarismo" coincidem no mesmo interesse normativo, mas Honneth lembra que assim como se distingue do liberalismo por tomar como orientação um universal de autorrealização, separa-se da ideia comunitária no

\footnotetext{
${ }^{8}$ Ibidem, p. 33.

${ }^{9}$ Ibidem, p. 34.

${ }^{10}$ Ibidem, p. 35-36.
} 
sentido em que esse universal está ligado à razão. ${ }^{11}$ Os principais autores que formam parte da teoria crítica nunca abandonaram a ideia hegeliana de que a práxis cooperativa e os valores partilhados devem possuir um carácter racional. O interesse deste enfoque está em ver a autorrealização individual ligada ao pressuposto de uma práxis comum que só pode ser o resultado da realização da razão. As relações de cooperação têm assim a função de incrementar a racionalidade social.

A teoria crítica diferencia-se do comunitarismo na forma como submete o universal, que a cooperação social encarna e realiza ao mesmo tempo, às coordenadas de uma fundamentação racional. Uma vez que, por mais diferentes que sejam os conceitos de razão usados de Horkheimer a Habermas, todos eles culminam na ideia final de que a consagração da práxis libertadora da cooperação não se realizará pelo vínculo afetivo, nem pelos sentimentos de pertença ou de coincidência, mas sim pela compreensão racional. O ideal de sociedade partilhado por todos os membros da teoria crítica alemã já não pode ser explicado na linguagem filosófica de Hegel, mas deverá ser ilustrado através de uma análise sociológica capaz de explicar o processo de formação patológica da razão. ${ }^{12}$

Os diversos enfoques da teoria crítica, segundo Honneth, ${ }^{13}$ com maior ou menor influência que cada um tenha de Marx, partilham uma premissa central na sua análise do capitalismo: as circunstâncias sociais que constituem as patologias das sociedades capitalistas têm a característica estrutural de velar precisamente aquelas ações que seriam o motivo de uma crítica pública forte. A teoria crítica tem que ampliar as tarefas a realizar na crítica da sociedade. Diferencia-se de outras abordagens da atualidade ao conectar a crítica das anomalias sociais com uma explicação dos processos que em geral tenham contribuído a velá-las. Há que completar a crítica normativa com elementos de explicação histórica: ao não se encontrar um universal racional, o que constitui a patologia social do presente, tem que explicar-se causalmente o processo histórico de deformação da razão, de forma a permitir entender a não tematização pública das anomalias sociais. Honneth acrescenta ao conceito de razão da teoria crítica a necessidade de incluir critérios novos e alheios, não ocidentais, de modo a que o conceito de racionalidade possa ampliar-se e diferenciar-se de forma permanente para poder dar conta do carácter multiforme dos processos sociais de aprendizagem. ${ }^{14}$

Podemos concluir com Honneth, ${ }^{15}$ que é uma versão pós-idealista da ideia hegeliana de realização da razão a que proporciona o sustentáculo neces-

\footnotetext{
11 Ibidem, p. 36.

12 Ibidem, p. 36-37.

13 Ibidem, p. 38-39.

14 Ibidem, p. 41.

15 Ibidem, p. 41-42.
} 
sário para a ideia que constitui o núcleo mais profundo de toda a tradição de Horkheimer a Habermas: que o processo de racionalização social foi interrompido ou condicionado de tal modo por características estruturais próprias unicamente do capitalismo e que têm como resultado inevitável as patologias que acompanham a perda de um universal racional.

Os principais representantes da teoria crítica, segundo Honneth, "partilham o mesmo esquema formal de diagnóstico do capitalismo como uma condição social de racionalidade bloqueada ou parcializada", bem como a ideia de qual a terapia adequada: "as forças que podem contribuir a superar a patologia social devem provir dessa mesma razão cuja realização está sendo impedida pela forma de organização social do capitalismo" ${ }^{16}$ Sem subestimar a sua importância no conjunto da teoria crítica, aqui revela-se fundamental a influência de um teórico marcante do pensamento moderno: Sigmund Freud. A mesma importância que têm Hegel, Marx, Weber e Lukács para o conteúdo central da Teoria Crítica, deverá ser atribuída à psicanálise de Freud, donde retiram a ideia central de que as patologias sociais expressam-se sempre em sofrimento que mantém vivo o interesse pelo poder emancipador da razão.

O projeto da teoria crítica pretendeu recuperar para os seres humanos a totalidade das suas capacidades, coincidindo neste objetivo com uma ampliação do marxismo. Segundo Calhoun, ${ }^{17}$ a teoria crítica apoiando-se no jovem Marx, principalmente no primeiro capítulo de Capital, e na análise de Luckács da reificação, procurava mostrar como a história humana fora capaz de alienar as capacidades humanas. A crítica operava-se pela desfetichização (defetischisierung), pelo diagnóstico das relações desumanas, nas quais os indivíduos eram simples mediações entre coisas, de forma a possibilitar a transformação social. Assim, neste exercício, a teoria assumiria a centralidade ao revelar a forma de consciência onde eram constituídas e mantidas as relações reificadas de capital.

O combate à reificação e à alienação está relacionado com a crítica ao positivismo que ocupou Horkheimer e seus correligionários durante grande parte dos seus trajetos. A ciência social positivista ao aceitar o mundo tal como ele existe e ao reproduzir a reificação de forma acrítica, através da qual o conteúdo humano fora removido das instituições e processos sociais, impede o reconhecimento da existência de possibilidades de mudança essencial. Através desta reificação foi possível tratar os aspetos da humanidade como se fossem simplesmente aspetos da natureza, tratar os factos sociais como coisas, segundo a inspiração de Durkheim. ${ }^{18}$

\footnotetext{
${ }^{16}$ Ibidem, p. 45.

${ }^{17}$ CALHOUN, ob. cit. p. 452-453.

${ }^{18}$ Ibidem, p. 453.
} 
Segundo Calhoun, ${ }^{19}$ a teoria crítica extravasava do pensamento proletário, representando um meio de pensar a totalidade social, que deslocaria a visão empírica e parcial do proletariado, resultante da sua posição de classe, para a visão de uma sociedade sem classes e não estruturada pela injustiça. A teoria crítica não partia de um grupo social específico, mas de um grupo de indivíduos preocupados em questionar a estrutura mais básica da totalidade da sociedade, de forma a apontar as possibilidades da sua transcendência. Considerando-se a teoria crítica nesta altura uma forma de marxismo, já se antecipava de alguma forma a crise posterior. Nota Calhoun, ${ }^{20}$ em primeiro lugar, que a teoria aplicada à situação empírica contemporânea apontava mais para uma nova barbárie do que para a sua transcendência. Em segundo lugar, Horkheimer evitou descrever uma potencial revolução e envolver-se politicamente, permanecendo o seu marxismo abstrato. Por último, o seu contributo para a teoria crítica foi mais consistente no domínio intelectual do que a nível social.

Para este autor, "no coração da teoria crítica encontrava-se a noção de crítica imanente, ou seja, um exercício da crítica que partia de dentro das categorias do pensamento existente, radicalizando-as e mostrando, a vários níveis, os seus problemas e as suas possibilidades não reconhecidas" ${ }^{21} \mathrm{~A}$ atividade da crítica é fundamental para revelar as tensões existentes entre o que existe e as suas possibilidades. Para a primeira geração da Escola de Frankfurt, o exercício da crítica imanente, enraizado na história, procedia da análise dialética das contradições internas a todas as épocas, a todas as situações e organizações sociais.

Com a razão reduzida ao domínio restrito do instrumental, chegando a ser posta ao serviço da indústria de morte nazi, tanto Horkheimer como Adorno receavam que o estado da sociedade não possibilitasse uma crítica verdadeiramente transformadora, ou que pudesse alicerçar qualquer ação que acabasse com a ordem social desumanizante e perigosa. ${ }^{22}$ Para Jay, ${ }^{23}$ esta postura pessimista decorria de vários fatores: a subjectivização da razão, conjuntamente com o capitalismo da livre iniciativa, parecia conceder poder aos indivíduos, mas tal era ilusório. $\mathrm{O}$ conformismo tinha tomado a forma de ideologia, combinado com uma crescente igualização das pessoas, respondendo cada uma unicamente ao seu interesse pessoal, enquanto consumidor, num mundo do capitalismo corporativo e da massificação cultural. Ajudada pela psicologia moderna que apresentava a adaptação e a integração social como o mais importante objetivo individual, o que

\footnotetext{
${ }^{19}$ Ibidem, p. 453-454.

${ }^{20}$ Ibidem, p. 454.

${ }^{21}$ Ibidem, p. 455.

${ }^{22}$ CALHOUN, ob. cit., p. 456-457.

${ }^{23}$ JAY, Martin. La Imaginación Dialética, p. 430-450.
} 
torna impossível equacionar criticamente os valores da realidade social existente. Já nenhum grupo social, incluindo o proletariado, os intelectuais e os artistas, parecia imune a esta mortificação da competência da razão para discernir os fins dos processos sociais.

Horkheimer, após a morte de Adorno, em forma de balanço e, talvez, de testamento da teoria crítica, na sua obra Teoria Crítica, ${ }^{24}$ define novamente a teoria crítica como aquilo que acrescenta à ciência algo de essencial, uma reflexão sobre si e sobre a sociedade existente. De certa forma desiludido da esperança revolucionária, aponta para a preservação da teoria crítica através da autonomia do indivíduo.

A meados da década de 1960, quando estalou a crise e os movimentos estudantis deram de novo especial relevo à política, os já envelhecidos teóricos críticos da primeira geração não estavam preparados para tal, sendo no entanto as suas ideias incorporadas nos discursos dos estudantes, quer na Alemanha, quer nos Estados Unidos, pp. 458-460). ${ }^{25}$

O teórico que mais se destaca nesta segunda geração é porventura Habermas. O seu trabalho inicial pretendia "repor a possibilidade de uma teoria crítica politicamente significativa", ${ }^{26}$ guiado pelo problema da relação entre teoria e prática. Assume o debate sobre a metodologia das ciências sociais, tentando ultrapassar a mera preocupação hermenêutica e a falácia das crenças positivistas, que distinguia o conhecimento objetivo da ação humana interessada. Habermas tentou possibilitar a unidade entre teoria e prática, expandindo o sentido de prática política, como a constituição de formas de vida conjunta que permita a realização plena do potencial humano.

Habermas afirma a importância de reabilitar a esfera pública, uma vez que, através de um modelo de comunicação pública poder-se-ia realizar o ideal de orientação racional da sociedade ${ }^{27}$ Através da teoria crítica, as pessoas poderiam se tornar conscientes do seu potencial por realizar e assim lutar contra aqueles que obstam à realização plena desses ideais.

Com as grandes transformações da esfera pública, como sejam a influência da comunicação mediática na sociedade de massas, bem como a diluição da diferenciação entre Estado e sociedade originada pela sociedade administrada, as decisões sociais deixaram de estar no discurso crítico dos/as cidadãos/ãs. Habermas, tal como os seus antecessores, foram conduzidos

\footnotetext{
${ }^{24}$ HORKHEIMER, Max. Teoría Crítica. Tradução de Edgardo Albizu e Carlos Luis. Buenos Aires: Amorrortu editores, (1968) 2003.

${ }^{25}$ CALHOUN, ob. cit., p. 458-460.

${ }^{26}$ Ibidem, p. 460.

${ }^{27}$ HABERMAS, Jürgen. Mudança estrutural da esfera pública. Tradução de Flávio R. Kothe. Rio de Janeiro: Tempo Brasileiro, (1962) 2003.
} 
a conclusões cada vez mais pessimistas. ${ }^{28}$ Como nos elucida Silvério da Rocha-Cunha:

a Teoria Crítica deparou com uma racionalização desencantada que substitui a religião pelos campos de concentração, o consumo e a pop-arte. Entre a dialética negativa de Adorno e a contrarrevolução e revolta de Marcuse, habita toda uma tradição ontológica que se preocupa com a necessidade de despir a natureza humana tal como é no mundo. ${ }^{29}$

A crise da praxis é vista como uma crise ontológica, que só pode ser superada pela luta por novas possibilidades do ser. Habermas abandonou o projeto de construir a teoria crítica a partir de uma fundação histórica, como os seus antecessores tinham feito. Enquanto Horkheimer e Adorno, segundo Gorän Therborn, ${ }^{30}$ deram ênfase às contradições e à negatividade da modernidade, sem no entanto projetarem uma alternativa melhor, ainda que utópica, Habermas não se deteve no pessimismo dos seus predecessores, tentou fundamentar a sua crítica não nos desenvolvimentos históricos e na alteridade de contextos, mas na definição de condições universais da vida humana baseadas numa evolução na comunicação. Ao invés de potenciar a dimensão crítica pela comparação de constituições sociais histórica e culturalmente específicas, propôs um conjunto de condições universais da vida humana, com base numa ideia lata de progresso evolutivo na comunicação. Habermas afastou-se da história de modo a recuperar a base para o otimismo. ${ }^{31}$ Com a pragmática universal fundamenta uma orientação otimista para a teoria crítica. Habermas transpôs para o seu trabalho seguinte sobre a ação comunicativa o potencial inacabado do projeto iluminista de modernidade. Ensaiar a resposta àquele ceticismo, "mediante a reconciliação entre a consciência individual capaz de pensar a monstruosidade e a consciência social que, a segrega e renova pela aparência, tem sido a tarefa habermasiana". ${ }^{32}$ Habermas acredita que as perspetivas sociológica, psicológica e filosófica podem unir-se através da linguagem, se esta for considerada como sistema autónomo, uma vez que a racionalidade comunicacional não isenta nenhum requisito de validade de possível exame crítico, dado que só na comunicação humana se podem cumprir requisitos de validade.

Habermas (2003) ao abandonar a expressividade particular da vida concreta, com vista à formulação normativa de uma Ética do Discurso, é criticado por alguns teóricos como Boaventura de Sousa Santos, que considera que

\footnotetext{
${ }^{28}$ CALHOUN, ob. cit., p. 462-463.

${ }^{29}$ ROCHA-CUNHA, Silvério da. O improvável que aconteceu E outros estudos em torno de dilemas do Direito e da Política numa era global. Ribeirão: Edições Húmus, 2008, p.236.

30 THERBORN, Gorän. Teoria crítica e o legado marxista do século XX. In B. Turner (ed.), Teoria Social. (pp. 52-81). Tradução de Rodrigo Valador. Algés: Difel, 1996, p. 53.

${ }^{31}$ CALHOUN, ob. cit., p. 463-464.

${ }^{32}$ ROCHA-CUNHA, ob. cit. p. 239.
} 
apesar de Habermas atingir o máximo de consciência possível da modernidade ocidental, não desiste de a transformar em receita universal, tendo conduzido ao empobrecimento cultural, na medida em que extrapola a forma de vida ocidental. ${ }^{33}$ Outra crítica prende-se com a impossibilidade de alcançar um diálogo sem dominação quando temos atores sociais com capitais culturais e políticos diferenciados. Ezequiel Ipar considera que o conteúdo normativo da teoria do discurso na democracia permite a crítica de problemas comuns das nossas sociedades contemporâneas que impedem o exercício da autonomia em termos igualitários. ${ }^{34}$ Para este Autor, a implementação da igualdade da modernidade política também permite uma convergência relativa às potencialidades ainda não exploradas nos diferentes processos de constituição dos Direitos Humanos. No entanto, ao depararem-se conflitos irredutíveis e dificilmente reconciliáveis através do uso público da razão, questões relacionados à opacidade transcultural do princípio discursivo/argumentativo que justifica a imparcialidade da democracia procedimental ou as marcas da herança colonial nas identidades segregadas que não se reduzem a dificuldades e obstáculos para sua participação no espaço público democrático, o potencial crítico da teoria habermasiana decai, ou inclusive pode transformar-se em obstáculo. ${ }^{35}$ Partindo de objeções como estas, Honneth pretende reformular a teoria crítica nos termos de uma teoria social do reconhecimento.

A teoria do reconhecimento, baseando-se no paradigma habermasiano da comunicação e no legado hegeliano e marxista da teoria crítica, propõe um modelo original de articulação, na forma de "dependência mútua" entre uma filosofia social fundada normativamente e uma sociologia convidada a apresentar estas normas à verificabilidade dos factos.

A reformulação teórica de Axel Honneth tem como tónica central os processos dinâmicos da formação de padrões normativos institucionalizados que só são estabelecidos por sucessivas confirmações recíprocas do reconhecimento intersubjetivo. ${ }^{36} \mathrm{O}$ reconhecimento apresenta-se assim como mediação onde se dá a construção da eticidade formal na modernidade, como resultado crescente das possibilidades expressivas dos indivíduos, no processo de reconhecimento recíproco entre confrontantes sociais. Para Honneth, além da evolução das formas de vida modernas, em que o entendimento funciona como meio de coordenação das ações, nas sociedades, que segundo Habermas, perderam as eticidades tradicionais, é necessário

\footnotetext{
${ }^{33}$ SANTOS, Boaventura de Sousa. Entrevista: O intelectual de retaguarda por Helena Mateus Jerónimo e José Neves. Análise Social, 204, xlvii (3.ำ), 2012, p. 691.

${ }^{34}$ IPAR, Ezequiel. "Crítica y emancipación: algunos dilemas de la teoría crítica". VIII Jornadas de Sociología, 2014. Disponível em: http://jornadassociologia.fahce.unlp.edu.ar. Acedido a 20/06/2018.

${ }^{35}$ Ibidem, p. 9.

${ }^{36}$ HONNETH, Axel. Luta por reconhecimento: para uma gramática moral dos conflitos sociais. Tradução de Jorge Telles de Menezes. Lisboa: Edições 70, (1992) 2011.
} 
fazer referência aos diferentes princípios normativos pelos quais os sujeitos se formam nas suas capacidades de auto-referência. Assim, se em Habermas a moralidade assume a prevalência metodológica para o diagnóstico das patologias sociais em quaisquer sociedades, uma vez que ela compreende o saber cultural implícito nas condições pragmático-formais da linguagem não constrangida, para Honneth, o potencial normativo das interações sociais extravasa das condições linguísticas isentas de coação. Em que a modernidade resulta não de um processo de evolução comunicativa, mas de um processo interpretativo do mundo da vida dos sujeitos implicados. Honneth diferencia-se de Habermas na ênfase dada às condições de reconhecimento em prejuízo das condições de comunicação.

Honneth opera uma viragem no ponto de vista do diagnóstico histórico em relação à abordagem habermasiana. Já não são as tensões entre sistema e mundo da vida que devem ser colocadas no centro da análise, mas as causas sociais responsáveis pela violação sistemática das condições de reconhecimento. Importa ter em conta as formas de desprezo que não entram na esfera pública e que não estão representadas de forma positiva nos atos de fala, que não são verbalizadas, e assim não podem depurar-se argumentativamente, fazendo sofrer os indivíduos desprezados.

A teoria de Honneth pretende articular de novo a filosofia social com as ciências empíricas, a teoria com a práxis, no que se pode interpretar como uma nova viragem sociológica no sentido da pretensão inicial do Instituto de Frankfurt. As ciências sociais terão agora a tarefa de seguir os sentimentos afetivos de desprezo e a gramática moral das exigências de justiça para encontrar na sociedade existente um excedente normativo que transcenda o modelo social dado.

\section{Repensar a Teoria Critica e sintese de pressupostos metodológicos}

Convocando uma síntese do que foi exposto anteriormente, com o contributo de Olivier Voirol, ${ }^{37}$ destacamos três ideias principais que caracterizam o projeto inicial, ao mesmo tempo sociológico e filosófico, da teoria crítica. Em primeiro lugar, este último está ancorado no materialismo histórico e na ideia de um desenvolvimento histórico voltado para o progresso - a partir da ideia que as forças práticas socialmente efetivas são realizadas pelos interesses de emancipação, pela razão e pela supressão dos fatores que

${ }^{37}$ VOIROL, Olivier. Axel Honneth et la sociologie. Reconnaissance et théorie critique à l'épreuve de la recherche sociale. In A. CAILLÈ (dir.), La quête de reconnaissance- nouveau phénomène social total.. Paris : Éditions La Découverte, 2007, p. 247. 
exercem dominação sobre os seres humanos. A teoria pode, portanto, apoiar-se neste exemplo prático para basear o seu ponto de vista e o seu apoio a este processo emancipatório a caminho de uma "sociedade governada pela razão", como diria Max Horkheimer. Em segundo lugar, ele propõe-se compreender os processos "patológicos" e a crescente irracionalidade que dificultam essa dinâmica através da pesquisa social. Contra as tendências irracionais que fragmentam a sociedade, a teoria crítica adota o ponto de vista da "totalidade" das relações sociais e proporciona os meios capazes de articular os saberes especializados de forma interdisciplinar. A sociologia desempenhará o papel de entender os mecanismos sociais e estruturais que não só impedem a implantação deste processo de emancipação, mas aumentam a dominação, como sejam a indústria cultural, o capitalismo monopolista, o fascismo, a autoridade, entre outros. Em terceiro lugar, esta articulação entre uma teoria normativa ancorada numa prática efetiva de emancipação e o recurso à sociologia, bem como à psicanálise, para compreender a dificuldade deste processo, é que constitui o plano de fundo deste programa no encontro da filosofia social com a pesquisa empírica.

Como vimos, os principais princípios orientadores da teoria crítica alemã foram sendo reformulados pelos diversos autores em diferentes momentos, mantendo como pano de fundo, a ideia principal que une os teóricos críticos: a articulação da teoria e prática na forma de uma crítica social imanente. Para Habermas (2002) as sucessivas gerações da teoria crítica tiveram a necessidade de reconstruir, compreender e produzir conceitos que sejam capazes de realizar uma transcendência imanente à realidade social que nos é dada, a partir de uma relação reflexiva com os processos de emancipação. ${ }^{38}$ Desde Horkheimer com o seu conceito de crítica e de trabalho social, Adorno com o seu conceito de mimesis com referências paralelas à etnografia e à crítica estética, ao conceito de Habermas de ação comunicativa, assente na pragmática formal e na teoria do discurso, até ao conceito de reconhecimento de Honneth, motivo fundamental de luta constante na interação, todos eles pretendem produzir as bases do conteúdo normativo da teoria crítica.

De forma a congregar uma síntese dos principais pressupostos metodológicos que terão implicação na crítica a desenvolver, convocamos o contributo de Calhoun, ${ }^{39}$ que define a teoria crítica como o conjunto de trabalho interpretativo que exige e desenvolve crítica nos seguintes quatro sentidos:

1. Uma relação de tensão e crítica com o mundo social contemporâneo, na qual se admita que a ordem social existente não esgota todas as possibilidades e na qual se procurem resultados positivos para a ação

${ }^{38}$ HABERMAS, Jürgen. A inclusão do outro. Tradução de George Sperber e Paulo Astor Soethe. São Paulo: Edições Loyola, 2002.

${ }^{39}$ CALHOUN, ob. cit. p. 471-473. 
social. Implica uma relação séria do/a cientista com o seu mundo social, de forma a descrever esse mundo nos termos das suas características relevantes para ação prática, da mesma forma que deverá relacioná-lo com diferentes contextos sociais e temporais.

2. Uma descrição e explicação críticas das condições históricas, culturais, sociais e pessoais, das quais depende a própria atividade do cientista. Trata-se acima de tudo de compreender a totalidade da formação social que concede a cada um a ocasião e as ferramentas para a reflexão teórica.

3. Uma contínua verificação crítica das categorias constitutivas e dos quadros conceptuais de entendimento utilizados pelo/a cientista, incluindo a análise da construção histórica desses quadros. Se pretendemos examinar criticamente os conceitos que incorporamos nas teorias, precisamos de os surpreender no processo da sua criação histórica, tendo bem presente que nenhuma tentativa de especificação operacional poderá estar imune à sua história.

4. Uma confrontação verdadeiramente crítica com outros trabalhos de análise do social, de forma a determinar os seus pontos fortes e fracos, capaz de desvendar as razões das suas omissões e incompreensões e de incluir os seus contributos num corpo de trabalho mais consistente. Assim, as teorias passadas não serão apenas modelos a seguir, mas percebidas como trabalhos delimitados em determinados contextos históricos diferentes dos nossos.

Como forma de elucidar este último ponto, importa perceber que a confrontação entre teorias raramente se resolve pela vitória do verdadeiro sobre o falso, uma vez que os investigadores e as investigadoras não trabalham num mundo dicotómico de respostas certas ou erradas, ou num movimento epistemológico de deslocação entre falsidade e verdade. Mas sim, naquilo que Charles Taylor denominou como "ganho epistémico", ${ }^{40}$ referindo-se à transferência no interior de um campo de alternativas disponíveis de uma posição problemática para uma posição mais ajustada, o que não deve ser entendido numa perspetiva atemporal, abstrata e independente dos ambientes onde os seus autores e autoras se movem.

Podemos concluir que a teoria crítica, nos quatro sentidos elucidados, depende de mecanismos de análise histórica e não poderá aceitar as pretensões de objetividade que a isentem da mudança histórica e do discurso público. Nenhuma teoria está acabada. Todas as teorias deverão estar abertas à verificação fundamentada no discurso crítico. Assim, podemos aferir, como nos elucida Pilar Damião de Medeiros, "que através de uma constante revisão concetual; capacidade de enquadrar criticamente as novas condições históricas; elucidar as patologias sociais e denunciar as diversas

${ }^{40}$ TAYLOR, Charles. Sources of The Self: The Making of the Modern Identity. Cambridge: University Press, 1989, p. 199-208. 
formas de dominação, a teoria crítica mantém, indubitavelmente, a sua relevância e atualidade teórica". ${ }^{41}$

A teoria crítica não é uma invenção nem propriedade dos teóricos de Frankfurt. No entanto, estes contribuíram decisivamente na articulação de uma tradição intelectual fundamental que integra a teoria, bem como no modo como a teoria crítica poderia questionar o discurso da esfera pública. Nos dias de hoje, a teoria crítica é desenvolvida não só por Habermas, por Honneth, seu sucessor no Instituto de Frankfurt e pelos seus seguidores, mas também por um vasto leque de autores e autoras que trabalham a partir de diferentes abordagens.

Vários autores e autoras da América Latina, como Aníbal Quijano do Perú (2001), Edgardo Lander (2000) da Venezuela, Santiago Castro-Gómez (1998) e Óscar Guardiola Rivera (2002) da Colombia, Enrique Dussel (1977 e 1992) do México, Javier Sanjinés (2004) da Bolívia, Zulma Palermo (2005) da Argentina, Catherine Walsh (2005) do Equador, Paulo Martins (2012) do Brasil, Walter Mignolo (1995 e 2003), Arturo Escobar (2005), Freya Schiwy (2009), Fernando Coronil (1992), Nelson Maldonado-Torres (2006), Agustín Lao-Montes (2005), Ramón Grosfoguel (2003) e Margarita Cervantes-Rodríguez (2010) dos Estados Unidos da América salientaram a coexistência de diferentes epistemes ou formas de produzir conhecimentos entre intelectuais, tanto da academia, como dos movimentos sociais. ${ }^{42}$ Questionaram o desenho colonial e imperial da geopolítica dominante do conhecimento e a subalternização epistemológica, ontológica e humana que esta geopolítica tem promovido. Estes autores, assim como Boaventura de Sousa Santos (2000 e 2010) da academia portuguesa têm construído um pensamento decolonial a partir do entendimento que as geopolíticas do conhecimento constituem uma estratégia medular do projeto da modernidade; a defesa do conhecimento científico como única forma válida de produzir verdades sobre a vida humana e a natureza, como conhecimento que se julga universal, oculta, invisibiliza e silencia as outras epistemes. ${ }^{43}$ Para este pensamento crítico decolonial está implícita a ideia de que a colonialidade é constitutiva da modernidade, o que significa dizer que a modernidade em geral, mas particularmente em relação à América Latina, não pode ser entendida sem ter em conta seus nexos com os legados coloniais e as diferenças étnico-raciais que o poder moderno/colonial tem produzido nesta parte do mundo. ${ }^{44}$

${ }^{41}$ DAMIÂO de MEDEIROS, Pilar. Reflexões em torno da querela P. Sloterdik e J. Habermas. In M. NUNES da COSTA (org.), Teoria Crítica Revisitada. Universidade do Minho: Edições Húmus, p. 259.

${ }^{42}$ Vejam-se as obras correspondentes na "Referência bibliográfica" ao final do artigo.

${ }^{43}$ WALSH, Catherine. (Re)Pensamiento crítico y (de)colonialidad. En: C. WALSH, (edt), Pensamiento Crítico y matríz (de) colonial, Reflexiones Latinoamericanas. Universidad Andina Simón Bolívar (pp. 13-35). Quito: Editorial Abya-Yala, 2005, p. 17.

${ }^{44}$ Ibidem, p. 18. 
Optaremos por incluir aqui a contribuição de Santos, cujas apreciações da Escola de Frankfurt coincidem com as de autores e autoras latino-americanos/as, ao articular várias interrogações e dificuldades que a teoria crítica ocidental enfrenta, ao confrontar-se com práxis sociais diferentes daquela da modernidade europeia.

Segundo Santos (2000, p. 25),

a teoria crítica desdobrou-se em múltiplas orientações teóricas, estruturalistas, existencialistas, psicanalíticas e fenomenológicas, e os ícones analíticos mais salientes foram, talvez, classe, conflito, elite, alienação, dominação, exploração, racismo, sexismo, dependência, sistema mundial, teologia da libertação. ${ }^{45}$

Estes conceitos e as configurações teóricas a eles articuladas, ainda hoje integram o trabalho dos/as cientistas sociais. Podendo-se pensar que é tão fácil fazer teoria social crítica hoje como o era antes, Santos alerta-nos para as dificuldades, uma vez que muitos destes conceitos deixaram de ter a centralidade que tinham antes, ou, fruto de tanta reconstrução teórica, perderam alguma da sua força crítica. ${ }^{46}$

A teoria crítica, desde Horkheimer, concebe a sociedade como totalidade e propõe uma alternativa total ao que existe. Ora, para Santos, foi Foucault que mostrou não haver "qualquer saída emancipatória dentro deste regime de verdade, já que a própria resistência se transforma ela própria num poder disciplinar e, portanto, numa opressão consentida porque interiorizada". ${ }^{47}$ Santos ao evidenciar as falhas e omissões da ciência moderna, enfatiza a necessidade de procurar "regimes de verdade" alternativos, outras formas de conhecimento que têm sido marginalizadas, suprimidas e desacreditadas pela ciência moderna. Apresenta o nosso lugar como um lugar multicultural, com uma preocupação hermenêutica de desconfiança contra aparentes universalismos ou totalidades. $\mathrm{O}$ autor define a sua posição claramente, negando a existência de um princípio único de transformação social. O que há são futuros possíveis em concorrência com outros futuros alternativos. Não existe uma forma única de dominação. São inúmeras as suas faces, bem como são múltiplas as resistências e os agentes que as protagonizam. Assim, segundo o mesmo autor, não é possível reunir todas as resistências e agências numa teoria comum total. "Mais do que de uma teoria comum, do que necessitamos é de uma teoria de tradução que torne as diferentes lutas mutuamente inteligíveis e permita aos atores coletivos «conversarem» sobre as opressões a que resistem e as aspirações que os animam". ${ }^{48}$ É através da "tradução", que Santos designa por hermenêutica

\footnotetext{
${ }^{45}$ SANTOS, Boaventura de Sousa. Crítica da razão indolente: contra o desperdício da experiência (Vol. 1). Para um novo senso comum: a ciência, o direito e a política na transição paradigmática. Porto: Edições Afrontamento, 2000, p. 25.

${ }^{46}$ Ibidem, p. 25.

${ }^{47}$ Ibidem, p. 26.

${ }^{48}$ Ibidem, p. 27.
} 
diatópica que as necessidades, aspirações e práticas de uma determinada cultura podem ser compreendidas por outra cultura..$^{49} \mathrm{O}$ autor não propõe uma grande teoria para o conhecimento-emancipação, mas uma "teoria da tradução intercultural" que sirva de fundamentação epistemológica às práticas emancipatórias, todas elas transitórias e inacabadas e, assim, somente sustentáveis se estiverem ligadas entre si.

Na modernidade eurocêntrica, para Santos, ${ }^{50}$ apesar de inscritas duas formas de conhecimento na sua matriz: o conhecimento-regulação e o conhecimento-emancipação, verifica-se que o conhecimento-regulação tem vindo a dominar totalmente o conhecimento-emancipação. A razão prende-se com o modo como a ciência moderna ascendeu e institucionalizou-se como conhecimento dominante. Para este autor, a teoria crítica ao descurar a crítica epistemológica da ciência moderna e apesar de ambicionar ser uma forma de conhecimento-emancipação converteu-se em conhecimento-regulação, uma vez que procura desenvolver as possibilidades emancipatórias dentro do paradigma dominante. Ora, Santos defende a tese que "deixou de ser possível conceber estratégias emancipatórias genuínas no âmbito do paradigma dominante já que todas elas estão condenadas a transformar-se em outras tantas estratégias regulatórias". ${ }^{51}$ Santos propõe uma crítica radical do paradigma dominante, tanto dos seus modelos regulatórios como dos seus modelos emancipatórios, de forma que a teoria crítica pós-moderna possa anunciar o paradigma emergente.

Santos propõe uma teoria crítica pós-moderna que recuse o vanguardismo e ambicione transformar-se num senso comum emancipatório.

Porque é auto-reflexiva, sabe que não é através da teoria que a teoria se transforma em senso comum. A teoria é a consciência cartográfica do caminho que vai sendo percorrido pelas lutas políticas, sociais e culturais que ela influencia tanto quanto é influenciada por elas. ${ }^{52}$

De forma a poder contribuir para novos sensos comuns emancipatórios, a teoria deverá identificar e caraterizar as constelações de regulação, as múltiplas opressões das sociedades capitalistas, a pluralidade dos agentes sociais, dos instrumentos sociais e dos conhecimentos suscetíveis de serem mobilizados em constelações emancipatórias. ${ }^{53}$ A partir daqui estarão lançadas as sementes de novos sensos comuns.

Posteriormente, Santos na sua obra Descolonizar el saber - reinventar el poder (2010) vem completar o diagnóstico das dificuldades e dilemas que a teoria crítica desenvolvida na tradição ocidental tem enfrentado

\footnotetext{
${ }^{49}$ Ibidem, p. 31.

50 Ibidem, p. 29.

51 Ibidem, p. 16.

52 Ibidem, p. 37.

53 Ibidem, p. 327.
} 
nos últimos trinta anos. As dificuldades são ao mesmo tempo políticas, teóricas e epistemológicas. "São dificuldades quase dilemáticas porque ocorrem na própria imaginação política que sustém a teoria crítica e, em última instância, a política emancipadora" ${ }^{54} \mathrm{O}$ autor formula a primeira dificuldade da imaginação política desta forma: "é tão difícil imaginar o fim do capitalismo como é difícil imaginar que o capitalismo tenha fim" ${ }^{55}$ Esta dificuldade, segundo o autor, tem sido fraturante no pensamento crítico, principalmente em duas vertentes que sustentam políticas distintas de esquerdas. A primeira vertente deixou de se preocupar com o fim do capitalismo e centrou a sua atividade no desenvolvimento de propostas que incluindo o capitalismo, permitam reduzir os custos sociais do sistema capitalista. A social-democracia, o "keynesianismo" e o Estado de Bem-Estar e de desenvolvimento dos anos sessenta do século passado constituíram os principais modelos políticos desta vertente. A segunda vertente da tradição crítica, prosseguindo o pensamento de Santos, apesar de não se deixar bloquear pela primeira dificuldade, vive intensamente a segunda dificuldade: a de imaginar como será o fim do capitalismo. ${ }^{56}$ Esta é uma dupla dificuldade já que, por um lado, reside em imaginar alternativas pós-capitalistas depois do fracasso do socialismo e, por outro, implica imaginar alternativas pré-capitalistas anteriores ao colonialismo. Para além disso,

esta dificuldade da imaginação política não está igualmente distribuída no campo político: se os governos imaginam o pós-capitalismo a partir do capitalismo, os movimentos indígenas imaginam o pós-capitalismo a partir do pré-capitalismo. No entanto, nem uns nem outros imaginam o capitalismo sem o colonialismo interno. ${ }^{57}$

Com a exploração capitalista ao combinar-se com a dominação do colonialismo interno, mais difícil será estabelecer um pacto entre as classes mais afetadas, pois estas são atravessadas por identidades culturais e regionais que multiplicam as fontes dos conflitos e favorecem a sua institucionalização de uma forma cada vez mais problemática e precária. ${ }^{58}$

A segunda dificuldade da imaginação política, segundo Santos, "pode formular-se assim: é tão difícil imaginar o fim do colonialismo como é difícil imaginar que o colonialismo não tenha fim". ${ }^{59}$ Uma parte do pensamento crítico deixou-se bloquear pela primeira dificuldade e o resultado tem sido a negação da existência do próprio colonialismo a partir do processo

\footnotetext{
${ }^{54}$ SANTOS, Boaventura de Sousa. Descolonizar el saber - reinventar el poder. Tradução de vários autores. Extensión universitária. Universidade de la República: Ediciones Trilce, 2010, p. 11.

${ }^{55}$ Ibidem, p. 11.

${ }^{56}$ Ibidem, p. 12.

${ }^{57}$ Ibidem, p. 12.

${ }^{58}$ Ibidem, p. 13.

${ }^{59}$ Ibidem, p. 14.
} 
que conduziu às independências, não sendo valorizadas as lutas étnico-raciais, mas sim a mestiçagem como sinal de superação do colonialismo. Ao contrário, a outra vertente da tradição crítica parte do pressuposto de que o processo histórico que conduziu às independências demonstra que o colonialismo interno não só se manteve depois das independências, como em alguns casos se agravou. A dificuldade em imaginar a alternativa ao colonialismo reside no fato deste não ser unicamente uma política de Estado, como sucedia durante o colonialismo de ocupação estrangeira. Ele "é uma gramática social muito vasta que atravessa a sociabilidade, o espaço público e o espaço privado, a cultura, as mentalidades e as subjetividades" ${ }^{60}$ O colonialismo tornou-se assim um modo de viver e de conviver entre aqueles que beneficiam dele e aqueles que o sofrem. Para esta vertente da tradição crítica a luta contra o capitalismo deverá ser conduzida paralelamente com a luta contra o colonialismo. Uma vez que a dominação de classe e dominação étnico-racial alimentam-se mutuamente, a luta pela igualdade não pode separar-se da luta pelo reconhecimento da diferença.

Devido ao protagonismo dos movimentos sociais indígenas, camponeses, afrodescendentes e feministas, principalmente no continente latino-americano, com as suas bandeiras de luta e com as dificuldades da imaginação política progressista já referidas, constituem-se as razões que determinam a necessidade de manter alguma distância em relação à tradição crítica eurocêntrica. Para além destes fatores, Santos (2010, p. 15) enuncia outros de raiz teórica que reforçam essa necessidade, como são a perda dos "substantivos críticos" e "a relação fantasmal entre a teoria e a prática".

Como já foi mencionado anteriormente, para além dos principais conceitos analíticos da teoria crítica terem perdido alguma centralidade e força crítica, Santos refere que a teoria crítica já não pode definir os termos do debate. Os novos movimentos sociais das últimas três décadas, ao mesmo tempo que reelaboram os antigos conceitos, introduzem novos conceitos que não têm precedentes na teoria crítica eurocêntrica, assim como não se expressam em nenhuma das línguas coloniais em que a teoria crítica foi construída. ${ }^{61}$

A última dificuldade que a teoria crítica enfrenta na perspetiva de Santos reside na enorme discrepância entre o que está previsto na teoria e as práticas mais transformadoras que têm surgido essencialmente no hemisfério sul.

Nos últimos trinta anos as lutas mais avançadas foram protagonizadas por grupos sociais (indígenas, camponeses, mulheres, afrodescendentes, piqueteros, desempregados) cuja presença na história não foi prevista pela

${ }^{60}$ Ibidem, p. 15.

${ }^{61}$ Ibidem, p. 16. 
teoria eurocêntrica. Organizaram-se muitas vezes com formas (movimentos sociais, comunidades eclesiais de base, piquetes, autogoverno, organizações económicas populares) muito distintas das privilegiadas pela teoria: o partido e o sindicato. Não habitam os centros urbanos industriais mas lugares remotos nas alturas dos Andes ou nas planícies da selva amazónica. Expressam suas lutas muitas vezes nas suas línguas nacionais e não em nenhuma das línguas coloniais em que foi redigida a Teoria Crítica. E quando suas demandas e aspirações são traduzidas nas línguas coloniais, não emergem os termos familiares de socialismo, direitos humanos, democracia ou desenvolvimento, mas sim dignidade, respeito, território, autogoverno, a vida boa, a Mãe Terra. ${ }^{62}$

Para Santos, esta discrepância entre teoria e prática foi bem visível no primeiro Fórum Social Mundial (FSM) realizado em Porto Alegre em 2001, onde se percebeu que o fosso entre as práticas de esquerda e as teorias clássicas de esquerda era mais profundo do que nunca. "A cegueira da teoria acaba na invisibilidade da prática e, assim, na sua sub-teorização, enquanto que a cegueira da prática acaba na irrelevância da teoria". ${ }^{63} \mathrm{~A}$ cegueira da teoria foi observada na forma como os partidos convencionais de esquerda e os seus intelectuais minimizaram o significado do FSM, enquanto que a cegueira da prática manifesta-se no desprezo que muitos ativistas do FSM expressam pela rica tradição teórica da esquerda eurocêntrica e pela sua renovação.

As causas desta relação fantasmal entre a teoria e a prática são múltiplas, mas Santos salienta a mais importante:

enquanto a teoria crítica eurocêntrica foi construída em poucos países europeus (Alemanha, Inglaterra, França, Rússia e Itália) com o objetivo de influenciar as lutas progressistas nessa região do mundo, as lutas mais inovadoras e transformadoras estão ocorrendo no Sul num contexto de realidades socio-político-culturais muito distintas. ${ }^{64}$

Esta distância fantasmal entre a teoria e a prática não resulta unicamente da diferença de contextos, é também epistemológica e ontológica. Pois estes novos movimentos sociais constroem as suas semânticas e lutas a partir de concepções ontológicas sobre a vida e o ser muito diferentes do imediatismo e individualismo ocidentais. Os seres são comunidades de seres antes de serem indivíduos e nessas comunidades estão presentes os antepassados, os animais e a Mãe Terra. Estas cosmovisões não ocidentais, segundo Santos, obrigam-nos a um trabalho de tradução intercultural para que possam ser entendidas e valorizadas. ${ }^{65}$

\footnotetext{
${ }^{62}$ Ibidem, p. 17.

${ }^{63}$ Ibidem, p. 18.

${ }^{64}$ Ibidem, p. 18.

${ }^{65}$ Ibidem, p. 19.
} 
Durante muito tempo a teoria crítica teve como referência as lutas contra a opressão, a exclusão e o fim do capitalismo. Nas últimas décadas, as lutas sociais contribuíram para ampliar enormemente o campo político das lutas contra a opressão e a exclusão e o fim do capitalismo passou a articular-se com o fim do sexismo e do colonialismo.

Como vimos, o autor ao elencar as dificuldades e dilemas que a teoria crítica enfrenta propõe que para superá-las será importante criar alguma distância teórica e epistemológica em relação à tradição ocidental. Como Santos explica: "a distância que proponho em relação à tradição crítica eurocêntrica tem por objetivo abrir espaços analíticos para realidades surpreendentes, porque são novas ou porque até agora foram produzidas como não existentes, donde podem brotar emergências libertadoras" ${ }^{66}$ Para Santos, manter uma distância não significa descartar toda a riqueza da teoria crítica ocidental e muito menos ignorar as suas possibilidades de emancipação. Significa estar, ao mesmo tempo, dentro e fora do que se critica, de tal modo que se torne possível o que Santos denomina de "dupla sociologia transgressiva das ausências e das emergências", o que consiste essencialmente em contrapor as epistemologias do Sul às epistemologias dominantes do Norte Global. ${ }^{67}$

Assim, como defende Santos,

as epistemologias do sul deverão dialogar, argumentar e contra argumentar com outras epistemologias. Este diálogo deverá ser duplo: por um lado, é uma confrontação com o pensamento hegemónico do Norte Global, em que todas as epistemologias positivistas entram neste conceito; mas, por outro lado, é também um diálogo e uma confrontação com o pensamento crítico eurocêntrico, cuja formulação mais brilhante se concretiza na Escola de Frankfurt, desde a época de Theodor W. Adorno e Max Horkheimer. ${ }^{68}$

Pretendemos neste estudo contribuir para este diálogo, explorando os contributos da teoria crítica alemã, de Horkheimer a Honneth, e propondo o debate com outras linhas de pensamento crítico, como é a abordagem de Santos.

Ao convocar as abordagens de dois autores reconhecidos internacionalmente como grandes teóricos contemporâneos da teoria social e política, como são Axel Honneth e Boaventura de Sousa Santos, não é nossa intenção fazer um balanço das suas teorias, mas sim discutir alguns aspetos dessas teorias, procurando um núcleo comum, de forma a contribuir para uma

${ }^{66}$ Ibidem, p. 19.

${ }^{67} \mathrm{Ibidem}$, p. 21.

${ }^{68}$ SANTOS, Boaventura de Sousa. Introducción: las Epistemologías del Sur. Formas-Outra: Saber, nombrar, narrar, hacer. Edición de las actas del "IV Training Seminar del Foro de Jóvenes Investigadores em Dinámicas Interculturales. Centro de Estudios y Documentación Internacionales de Barcelona: CIDOB Edicions, 2011, p. 18. 
teoria crítica capaz de responder aos desafios do tempo presente. Apesar das diferenças entre estes pensadores, como Josué Pereira da Silva (2014) sublinha, ${ }^{69}$ ambos procuram um paradigma intersubjetivo que se distingue tanto das abordagens holistas como individualistas. Um segundo ponto em comum será a ênfase na dimensão político-normativa que as suas teorias comportam, na medida em que ambicionam um horizonte além do existente, apontando caminhos para a mudança social. Daí percebe-se a invocação por parte destes autores de conceitos como justiça, direitos humanos, reconhecimento, autonomia emancipação social, entre outros.

Ao trabalharmos estas abordagens nos seus aspetos complementares, não podemos ignorar que Santos está fortemente empenhado em construir uma alternativa às teorias do Norte Global. Neste sentido, a teoria de Santos também pode ser vista como um contraponto crítico à construção teórica de Honneth. Mantendo a vigilância epistemológica, consideramos que estas duas propostas teóricas, críticas e abrangentes poderão contribuir para a construção de alternativas teóricas.

Prosseguindo com a teoria crítica alemã, cujo horizonte cultural se constituiu principalmente no processamento da história do pensamento europeu de Hegel a Freud, esta conta com a possibilidade de considerar a história seguindo o fio condutor da razão. Ora, segundo Honneth (2009, p. 28), nada resultará mais estranho à geração atual, que cresceu com consciência da pluralidade e do fim dos "grandes relatos", que essa fundamentação da crítica da sociedade na filosofia da história: a "ideia de uma razão historicamente ativa" om que todos os representantes da Escola de Frankfurt concordaram, de Horkheimer a Habermas, tem de resultar incompreensível onde já não é possível reconhecer a unidade de uma só razão na pluralidade de convicções fundadas. Da mesma forma, seguindo o raciocínio de Honneth, ${ }^{70}$ a ideia mais ampla de que o progresso dessa razão está travado ou interrompido pela organização capitalista da sociedade também será estranha, uma vez que já não é possível ver o capitalismo como um sistema unitário de racionalidade social.

As mudanças políticas das últimas décadas não deixaram de influenciar o estatuto da crítica na sociedade. Com a consciência da pluralidade cultural, bem como com a experiência das disparidades dos movimentos de emancipação social, foram bastante reduzidas as expetativas acerca do que deve e pode ser a crítica. Como nos refere Honneth (2009, pp. 28-29), em muitos casos a crítica já não é concebida como forma de reflexão de uma

\footnotetext{
${ }^{69}$ SILVA, Josué Pereira da. O que é crítico na sociología crítica?. Teoria social no limite: novas frentes/fronteiras na teoria social moderna, 2014. Disponível em: http://www.anpocs.org/portal/ index.php?option=com_docman\&task=doc_view\&gid=9213\&Itemid=456. Acedido a 20/01/2017. ${ }^{70}$ HONNETH, Axel. Patologías de la Razón. Tradução de Griselda Mársico. Madrid: Katz, 2009 , p. 28.
} 
racionalidade que deva estar ancorada no processo histórico. Por sua vez, a teoria crítica insiste, de uma maneira singular, nas palavras de Honneth,

numa mediação de teoria e história no conceito de uma razão socialmente ativa: o passado histórico deve entender-se em sentido prático como um processo de formação cuja deformação patológica por parte do capitalismo só pode superar-se se os implicados iniciam um processo de ilustração. ${ }^{71}$

Este modelo intelectual de mediar a teoria e a história é que funda a unidade da teoria crítica alemã na multiplicidade das suas vozes: seja na forma positiva do primeiro Horkheimer, de Marcuse e de Habermas, ou na forma negativa de Adorno e Benjamim, o pano de fundo dos vários projetos é constituído sempre pela ideia que um processo histórico de formação foi distorcido pela situação social de tal forma que só pode corrigir-se na prática. Segundo Honneth, ${ }^{72}$ assinalar o legado da teoria crítica para o novo século deverá significar resgatar nessa ideia de uma patologia social da razão a carga negativa que todavia contém para o pensamento atual; contra a tendência a reduzir a crítica da sociedade a um empreendimento de posicionamento normativo, situacional ou local, é necessário fazer-se compreensível a relação em que se encontra com as pretensões de uma razão que se foi formando na história.

\section{Considerações finais}

A teoria crítica, de Horkheimer a Habermas, guia-se pela ideia de que a patologia da racionalidade social conduz a incapacidades que se expressam na experiência dolorosa da perda de faculdades racionais. Para Honneth, ${ }^{73}$ esta ideia conflui na tese forte, essencialmente antropológica, que o comportamento dos sujeitos humanos não pode ser indiferente à restrição das suas faculdades racionais; uma vez que a sua autorrealização prende-se com o pressuposto da ação cooperativa da sua razão, eles não conseguem evitar o sofrimento psíquico pela sua deformação. Honneth destaca que "ter compreendido que entre uma psique intata e uma racionalidade não distorcida deve haver uma relação interna é talvez o impulso mais forte que a teoria crítica recebeu de Freud". ${ }^{74}$

Os vários autores que constituem o núcleo central da teoria crítica partilham a mesma ideia de que o desejo de emancipar-se do sofrimento só pode satisfazer-se recuperando uma racionalidade intata. Para Honneth,

${ }^{71}$ Ibidem, p. 29.

${ }^{72}$ Ibidem, p. 29.

${ }^{73}$ Ibidem, p. 48.

${ }^{74}$ Ibidem, p. 48. 
este pressuposto comporta riscos, mas é o que permite estabelecer um vínculo da teoria com a prática, diferente do que era dado pelas tradições marxistas. ${ }^{75}$ Os defensores da teoria crítica não partilham com os seus destinatários um conjunto de objetivos comuns ou projetos políticos, mas um conjunto de razões em comum que mantêm em aberto o presente patológico à possibilidade de uma transformação por intermédio da compreensão racional. Apesar das deformações ou parcializações da racionalidade social e prosseguindo o pensamento de Honneth, ${ }^{76}$ só na medida em que se pode contar com o impulso racional do ser humano em ampliar a razão é que a teoria poderá remeter-se reflexivamente a uma praxis potencial, em que as suas explicações são desenvolvidas com o objetivo de libertar do sofrimento. Assim, a teoria crítica, segundo Honneth, ${ }^{77}$ na forma em que foi desenvolvida de Horkheimer a Habermas, só poderá subsistir no futuro se não renunciar a demonstrar a existência deste tipo de interesse. Para Honneth, o projeto da teoria crítica só terá futuro se desenvolver um conceito realista de "interesse emancipador", que supõe um núcleo inextinguível de capacidade de reação racional dos sujeitos aos interesses da crítica.

Julgamos que o conjunto de ideias até aqui apresentadas mostra-nos o conteúdo central do legado da teoria crítica alemã. Enquanto não se abandonar a intenção de entender a teoria crítica como forma de reflexão de uma razão historicamente ativa, de forma alguma se poderá renunciar ao motivo normativo do universal racional, à ideia de patologia social da razão e ao conceito de interesse emancipador. Por outro lado, também ficou demonstrado que esses três elementos concetuais não podem conservar-se hoje na forma em que os membros da Escola de Frankfurt os desenvolveram originalmente; todos eles precisam de ser reformulados, de uma mediação com o estado atual do nosso conhecimento.

Com o contributo de Santos, que coincide com as perspetivas de autores e autoras latino-americanas, verificamos a necessidade de atualização dos princípios orientadores da teoria crítica frente a um mundo mais vasto do que o europeu. A teoria crítica deverá expandir o seu repertório e tornar-se mais sensível às diferentes dinâmicas sociais e históricas, acrescentando as reflexões feitas a partir das múltiplas modernidades. Pois, para este pensador crítico pós-moderno, fazer crítica implica considerar o primado da práxis social frente à teoria, que é um dos momentos reflexivos dessa práxis.

\footnotetext{
75 Ibidem, p. 50.

${ }^{76}$ Ibidem, p. 51.

77 Ibidem, p. 51.
} 


\section{Referências bibliográficas}

CERVANTES-RODRÍGUEZ, Margarita. International migration in Cuba: accumulation, imperial designs, and transnational social fields. Pennsylvania State University Press, 2010

CALHOUN, Craig. A Teoria Social e a Esfera Pública. In B. TURNER (ed.), Teoria Social. Tradução suportada pela Fundação Luso-Americana. Algés: Difel, pp. 437479, 1996.

CASTRO-GÓMEZ, Santiago. “Geografías poscoloniales y translocalizaciones narrativas de lo latino-americano. La crítica al colonialismo en tiempos de la globalización". En: FOLLARI, Roberto y LANZ Rigoberto (comp.): Enfoques sobre Posmodernidad en América Latina. Editorial Sentido, Caracas, 1998. pp. 155-182.

CORONIL, Fernando. Beyond Occidentalism: Towards Post-imperial Geohistorical Categories. University of Michigan Press, 1992.

DAMIÂO de MEDEIROS, Pilar. Reflexões em torno da querela P. Sloterdik e J. Habermas. In M. NUNES da COSTA (org.), Teoria Crítica Revisitada. Universidade do Minho: Edições Húmus, pp. 253-264, 2013.

DUSSEL, Enrique. Filosofía ética de la liberación. Vol. III. Niveles concretos de la ética latinoamericana. Buenos Aires: Ediciones Megápolis, 1977

DUSSEL, Enrique. El encubrimiento del Indio: 1492. Hacia el origen del mito de la modernidad. México, D. F.: Cambio XXI, 1992.

ESCOBAR, Arturo. Mas allá del Tercer Mundo. Globalización y Diferencia. Bogotá: Instituto Colombiano de Antropologia e História, 2005.

GROSFOGUEL, Ramón. Colonial Subjects: Puerto Ricans in a Global Perspective. Berkeley: University of California Press, 2003.

HABERMAS, Jürgen. A inclusão do outro. Tradução de George Sperber e Paulo Astor Soethe. São Paulo: Edições Loyola, 2002.

HABERMAS, Jürgen. Mudança estrutural da esfera pública. Tradução de Flávio R. Kothe. Rio de Janeiro: Tempo Brasileiro, (1962) 2003.

HONNETH, Axel. Luta por reconhecimento: para uma gramática moral dos conflitos sociais. Tradução de Jorge Telles de Menezes. Lisboa: Edições 70, (1992) 2011.

HONNETH, Axel. Patologías de la Razón. Tradução de Griselda Mársico. Madrid: Katz, 2009.

HORKHEIMER, Max. The Present Situation of Social Philosophy and the Tasks of an Institute for Social Research. In Between Philosophy and Social Science: Selected Early Writings Studies in Contemporary German Social Thought. Tradução de G. Frederick Hunter, Matthew S. Kramer, e John Torpey. Cambridge: MIT Press, (1931) 1993.

HORKHEIMER, Max. Teoría Crítica. Tradução de Edgardo Albizu e Carlos Luis. Buenos Aires: Amorrortu editores, (1968) 2003.

IPAR, Ezequiel. "Crítica y emancipación: algunos dilemas de la teoría crítica”. VIII Jornadas de Sociología, 2014. Disponível em: http://jornadassociologia.fahce.unlp. edu.ar. Acedido a 20/06/2018. 
JAY, Martin. La Imaginación Dialética: Una Historia de la Escola de Frankfurt. Tradução de Juan Carlos Curutchet. Madrid: Taurus, (1974) 1989.

LANDER, Edgardo (ed.). La colonialidad del saber: eurocentrismo y ciências sociales. Perspectivas latinoamericanas. Caracas: Facultad de Ciencias Económicas y Sociales (FACES-UCV), Instituto Internacional de la UNESCO para la Educación Superior en América Latina y el Caribe (IESALC), 2000.

LAO-MONTES, Agustín. "Afro-Latina Difference and the Politics of Decolonization" in Grosfoguel Ramon et al, ed. Latinos in the World-System. Paradigm Press, 2005.

MALDONADO-TORRES, Nélson. "Pensamento crítico desde a subalteridade: os Estudos Etnicos como ciências descoloniais ou para a transformação das humanidades e das ciências sociais no século XXI." Afro-Asia, no. 34: 105-29, 2006.

MARTINS, Paulo. La decolonialidad de América Latina y la heterotopia de una comunidade de destino solidaria. Buenos Aires: Fundación CICCUS; Estudios Sociológicos Editora, 2012.

MIGNOLO, Walter. “Os esplendores e as misérias da 'ciência': colonialidade, geopolítica do conhecimento e pluri-versalidade epistémica". En Boaventura de Sousa Santos (ed.). Conhecimento prudente para uma vida decente: um discurso sobre as 'ciências' revistado (pp. 631-671). Lisboa: Edições Afrontamento, 2003.

MIGNOLO, Walter. "Decires fuera de lugar: sujetos dicentes, roles sociales y formas de inscripción". Revista de crítica literaria latinoamericana, 11, 9-32, 1995.

QUIJANO, Aníbal. "Globalización, colonialidad y democracia”. En Instituto de Altos Estudios Diplomáticos Pedro Gual (ed.). Tendencias básicas de nuestra época: globalización y democracia. Caracas: Instituto de Altos Estudios Diplomáticos Pedro Gual, 2001.

PALERMO, Zulma. Desde la otra orilla. Pensamiento crítico y políticas culturales en América Latina. Córdoba: Alción Ed, 2005.

RIVERA, Oscar Guardiola. "In State of Grace. Ideology, Global Capitalism and the Geopolitics of knowledge". En Estados Unidos Neplanta. Views from South. Duke University Press, Durham, v.3,fasc. 1, pp. 15-24, 2002.

ROCHA-CUNHA, Silvério da. O improvável que aconteceu \& outros estudos em torno de dilemas do Direito e da Política numa era global. Ribeirão: Edições Húmus, 2008.

SANJINÉS, Javier. Mestizaje upside-down: aesthetic politics in modern Bolivia. University of Pittsburgh Press, 2004.

SANTOS, Boaventura de Sousa. Entrevista: O intelectual de retaguarda por Helena Mateus Jerónimo e José Neves. Análise Social, 204, xlvii (3.ํ), 2012.

SANTOS, Boaventura de Sousa. Introducción: las Epistemologías del Sur. Formas-Outra: Saber, nombrar, narrar, hacer. Edición de las actas del "IV Training Seminar del Foro de Jóvenes Investigadores em Dinámicas Interculturales. Centro de Estudios y Documentación Internacionales de Barcelona: CIDOB Edicions, 2011.

SANTOS, Boaventura de Sousa. Descolonizar el saber - reinventar el poder. Tradução de vários autores. Extensión universitária. Universidade de la República: Ediciones Trilce, 2010. 
SANTOS, Boaventura de Sousa. Crítica da razão indolente: contra o desperdício da experiência (Vol. 1). Para um novo senso comum: a ciência, o direito e a política na transição paradigmática. Porto: Edições Afrontamento, 2000.

SCHIWY, Freya. Indianizing Film: Decolonization, the Andes and the Question of Technology. Newark, N.J.: Rutgers University Press, 2009.

SILVA, Josué Pereira da. O que é crítico na sociología crítica?. Teoria social no limite: novas frentes/fronteiras na teoria social moderna, 2014. Disponível em: http://www.anpocs. org/portal/index.php?option=com_docman\&task=doc_view\&gid=9213\&Itemid=456. Acedido a 20/01/2017.

TAYLOR, Charles. Sources of The Self: The Making of the Modern Identity. Cambridge: University Press, 1989.

THERBORN, Gorän. Teoria crítica e o legado marxista do século XX. In B. Turner (ed.), Teoria Social. (pp. 52-81). Tradução de Rodrigo Valador. Algés: Difel, 1996.

VOIROL, Olivier. Axel Honneth et la sociologie. Reconnaissance et théorie critique à l'épreuve de la recherche sociale. In A. CAILLÈ (dir.), La quête de reconnaissancenouveau phénomène social total. (pp. 243-256). Paris : Éditions La Découverte, 2007.

WALSH, Catherine. (Re)Pensamiento crítico y (de)colonialidad. En: C. WALSH, (edt), Pensamiento Crítico y matríz (de) colonial, Reflexiones Latinoamericanas. Universidad Andina Simón Bolívar (pp. 13-35). Quito: Editorial Abya-Yala, 2005.

Endereço do Autor:

Escola de Ciências Sociais. Largo dos Colegiais, nº 2,

7004-516 Évora, Portugal

pfontes@uevora.pt 